\title{
Desenho e \\ interdisciplinaridade: \\ desenho em transversalidade
}

\author{
Daniela Zavisas Hladkyi*
}

Resumo A cooperação estabelecida entre os cursos de arquitetura do IAU-USP (São Carlos-SP, Brasil) e da FAUP (Porto, Portugal) incentivou a pesquisa e a produção de trabalhos em vários níveis. No âmbito da pós-graduação desenvolvemos um estudo onde o confronto entre os procedimentos disciplinares das duas escolas foi objeto de investigação. Neste artigo buscamos analisar relações que partem das disciplinas de desenho nos dois cursos onde sempre se faz presente uma intenção de interação e proximidade com as atividades de projeto arquitetônico. Buscamos compreender como essas relações se dão do ponto de vista pedagógico nas esferas da interdisciplinaridade, multidisciplinaridade e transdisciplinaridade.

Palavras-chave: interdisciplinaridade, desenho arquitetônico, projeto.

\section{Drawing and interdisciplinarity: drawing in transversality}

\begin{abstract}
The cooperation established between the architecture courses at IAU-USP (São Carlos-SP, Brazil) and FAUP (Porto, Portugal) encouraged the research and the production of works at various levels. In the scope of postgraduate studies, we developed a case study were the confrontation between the disciplinary procedures of the two colleges was the subject of the investigation. In this article we seek to analyze relationships that originate from the disciplines of drawing in the two courses where one always makes present an intention of interaction and proximity to the activities of architectural design. We seek to understand how these relationships take place from the pedagogical point of view in the spheres of interdisciplinarity, multidisciplinarity and transdisciplinarity.
\end{abstract}

Key words: interdisciplinarity, architectural drawing, design.

\section{Dibujo e interdisciplinaridad: dibujo en transversalidad}

Resumen La cooperación establecida entre los cursos de arquitectura del IAU-USP (São Carlos-SP, Brasil) y de la FAUP (Oporto, Portugal) incentivó la investigación y la producción de trabajos en varios niveles, en el ámbito del postgrado desarrollamos un estudio donde la confrontación entre los procedimientos disciplinarios de las dos escuelas fue objeto de investigación. En este artículo buscamos analizar relaciones que parten de las disciplinas de dibujo en los dos cursos donde siempre se hace presente una intención de interacción y proximidad con las actividades de diseño arquitectónico. Buscamos comprender cómo esas relaciones se dan desde el punto de vista pedagógico en las esferas de la interdisciplinariedad, multidisciplinariedad y transdisciplinariedad.

Palavras clave: interdisciplinariedad, dibujo arquitectónico, diseño. 
$\mathbf{N}^{2}$

a dissertação de mestrado "Desenho em observação: o ensino de desenho nos cursos de arquitetura da FAUP e do IAU" (HLADKYI, 2017) analisamos nos dois estudos de caso as visões, metodologias de ensino e estratégias pedagógicas de cada escola sobre o ensino do desenho para arquitetos. Focamos sobre o desenho à mão e suas potencialidades no ensino de arquitetura e processo de projeto, realizando uma leitura particular da fenomenologia da percepção (MERLEAU-PONTY, 2011), onde desmontamos $\mathrm{O}$ ato de desenhar a partir das instâncias visual, sensorial e cognitiva.

Tomando a dissertação por base e aprofundando questões derivadas desta, procuramos neste artigo analisar algumas tensões relativas à interdisciplinaridade que partem das disciplinas de desenho nas duas instituições. No estudo anterior selecionamos as disciplinas Desenho de Arquitetura I e Desenho de Arquitetura // no Instituto de Arquitetura e Urbanismo da Universidade de São Paulo (IAU-USP) no Brasil e Desenho 1 e Desenho 2 na Faculdade de Arquitetura da Universidade do Porto (FAUP) em Portugal, realizando uma descrição pormenorizada, contextualização, análise e leitura comparativa destas disciplinas pelas instâncias delimitadas pelo ato de desenhar. A pesquisa teve apoio financeiro do Conselho Nacional de Desenvolvimento Científico e Tecnológico (CNPq). Neste artigo, entretanto, tomamos as mesmas disciplinas como objeto de estudo, aprofundando a questão disciplinar e sua relação com o curso e entre cursos.

Interdisciplinar, multidisciplinar e transdisciplinar são termos muito recorrentes no campo da pedagogia geral. Porém, seus significados e usos devem ser aplicados com maior atenção e rigor. Resgataremos neste artigo suas definições e delimitações a fim de qualificar e revisar as relações entre disciplinas de desenho e projeto nos cursos de arquitetura selecionados. Dessa forma, verificaremos se há ou não interdisciplinaridade nos cursos ou mesmo se os termos têm sido aplicados corretamente, além de entender as questões que levam à busca por essas interações temáticas e contribuir para aprimorar essas relações.

\section{A interdisciplinaridade}

O uso da palavra interdisciplinaridade tem se tornado recorrente em muitos campos do saber. O seu emprego e popularização, muito além de um modismo, tem se propagado de forma a desgastar seu real significado, banalizado ou mesmo esvaziado este de sentido (POMBO, 2005, p.4). Acreditamos, porém, que esse consumo do termo possa acontecer porque a sua proposta em essência, é realmente interessante: relacionar conteúdos de diferentes disciplinas.

*Daniela Zavisas Hladkyi é arquiteta, monitora educacional profissional do SENAC São Carlos.
Além disso, há uma gama de palavras próximas à interdisciplinaridade, que muitos utilizam erroneamente com o mesmo sentido: multidisciplinaridade, pluridisciplinaridade e transdisciplinaridade. Alguns autores (FAZENDA, 2008; PIAGET, 1972; entre outros) 
buscaram defini-las e diferenciá-las, mas é certo que as fronteiras que demarcam a diferenciação entre elas podem ser muito tênues e flexíveis. Assim, concordamos com a proposta de Pombo (2005), que tenta simplificar as definições e buscar nas próprias palavras os seus fatores comuns e de derivação. Pombo $(2005$, p.5) em sua leitura a partir da etimologia das palavras, e analisando seus prefixos, simplifica as definições buscando a raiz comum entre elas, que é a disciplinaridade. Para a autora, a disciplinaridade está comprometida com a especialização dos saberes da ciência moderna do século XIX, que tem suas origens nos pensamentos de Galileu e Descartes, onde o estudo científico tem por base a subdivisão do todo em partes para análise e sua posterior recomposição de partes em todo. Esse princípio, inclusive, auxiliou na configuração das ciências, da própria universidade e comunidades acadêmicas. Diante disto, os prefixos multi, pluri, intere trans revelam como se dão as relações entre saberes, justapostos ou entrelaçados, hierarquicamente ou não. A multidisciplinaridade e pluridisciplinaridade propõem a justaposição de diversos olhares diferentes, colocá-los junto, lado a lado. A interdisciplinaridade torna as disciplinas inter-relacionadas, articulam-se, o trabalho se dá em conjunto, em "ação recíproca". Já a transdisciplinaridade traria um saber que se sobrepõe e atravessa diversas disciplinas, é um "ir além".

Para além das delimitações de cada termo específico, o que podemos destacar nesta família de palavras é a vontade antagônica que sua raiz determina: a de extravasar a disciplina, de tornar o tema menos monótono, agregando um pouco da complexidade do mundo atual e da colaboração entre partes. Pombo $(2005$, p.6) se refere a esta condição como "resistência à especialização", onde caberia à interdisciplinaridade o papel de pensar nossa condição fragmentada das ciências, ansiando por um saber unificado.

As universidades são historicamente lugares hierárquicos do saber, onde sua estrutura institucional revela não apenas seu sistema de gestão como sua organização da produção do conhecimento. No caso mais comum, para formar-se em determinado curso, o aluno deve frequentar e ser aprovado em um determinado número de disciplinas obrigatórias, podendo escolher livremente entre um número ínfimo de disciplinas optativas no próprio departamento ou em outras escolas. Algumas experiências propõem uma grade curricular mais flexível, que possibilita que o aluno escolha as disciplinas de seu interesse e o caminho a trilhar para se formar. Outras instituições não possuem disciplinas e sim unidades curriculares, tendo um entendimento de que as disciplinas são por demais compartimentadas e as unidades curriculares trabalhariam com as competências que os alunos devem desenvolver para atingir a sua formação, numa visão um pouco mais abrangente e global da formação profissional. Afinal, o que podemos observar é uma tendência de tentar integrar disciplinas e saberes, seja em instituições onde a organização curricular já é mais flexível, seja nas que ainda colocam os conteúdos em diversas "gavetas separadas". Nestas últimas, principalmente, visando facilitar e flexibilizar os currículos dos cursos, as propostas que mais tem se visto implantar são as atividades interdisciplinares.

\section{Desenho no IAU}

O Curso de Arquitetura e Urbanismo (CAU) do IAU-USP tem seu histórico de criação marcado pela interdisciplinaridade. Implantado em 1985, passou por cerca de 20 anos de discussões sobre seu plano de curso. Inicialmente baseado no plano de curso da 
Faculdade de Arquitetura e Urbanismo (FAU-USP) idealizado por Villanova Artigas na década de 1960 que se estruturava a partir de três eixos (Tecnologia, História e Projeto), ganhou adicionalmente o eixo de Representação e Linguagem. Acerca da diferenciação entre os planos de curso das duas escolas, Santos e Castral (2009, p.1) pontuam:

As áreas propostas representam uma espécie de eixo de integração vertical, no entanto se diferenciam da proposta da FAU-USP por terem em sua gênese momentos de integração entre os eixos e ter o Trabalho de Graduação Integrado (TGI) ao final do curso como momento onde se demanda aos alunos a síntese de todos os eixos.

O plano de curso que foi implantado em 1985 privilegiava as relações interdisciplinares e de síntese, seja as que se davam no nível das disciplinas, seja no nível dos eixos temáticos. Além disso, inovava ao tratar o tema da modernidade como ponto de partida para discussão de várias disciplinas do primeiro ano, abandonando uma sequência cronológica e linear, principalmente no eixo de História. As vanguardas modernas, a Bauhaus, a Gestalt e conceitos da Semiótica e teoria da comunicação foram fortes influências na estruturação das disciplinas e dos diálogos entre elas. Outro fator de interação entre disciplinas era a vontade de "restabelecer o vínculo entre arte e técnica" (SANTOS; CASTRAL, 2009, p.2), que se desdobrava na articulação entre Projeto diversas disciplinas que se desenrolavam junto a outros departamentos da Escola de Engenharia de São Carlos (EESC-USP). Somava-se a isso, o Estudo de Investigação Científica, onde os alunos se envolviam com as pesquisas desenvolvidas no departamento ou em atividades de extensão à comunidade. Por fim, a proposta de um Trabalho de Graduação Integrado, presente desde o início do curso, sempre reforçou essa vontade de formar um profissional com visão crítica e reflexiva, atualizada e capaz de sintetizar conteúdos e atuar na sociedade.

Outro objetivo estabelecido no projeto de 1985, como consequência dessa postura, era restabelecer o vínculo entre arte e técnica. Entre as ações, o projeto previa uma aproximação com os outros departamentos da Escola de Engenharia de São Carlos no sentido da definição de disciplinas mais articuladas ao ambiente do curso, evitando uma abordagem com caráter puramente instrumental, e possibilitando que esses conteúdos fossem trabalhados também nas outras disciplinas, principalmente nas da área de Projeto. (SANTOS; CASTRAL, 2009, p.2)

Apesar das revisões que o curso sofreu ao longo dos anos e mesmo o fato de ter se tornado um instituto independente da EESC-USP, o CAU-IAU ainda mantém essas principais características do plano de curso inicial. No eixo de Representação e Linguagem inserem-se as disciplinas de Desenho de Arquitetura, Matemática para Arquitetura, Plástica e Informática para Arquitetura no primeiro ano, Linguagens Visuais e Leituras Topográficas no segundo ano, e Linguagem da Arquitetura e da Cidade no quarto ano. Estas disciplinas tem o papel de introduzir os códigos utilizados pelos arquitetos e discutir a representação gráfica. Esta configuração de disciplinas é muito próxima à implantada no início do curso, que tomou forma principalmente nos anos 1990.

Até a década de 1990, havia na grade curricular três disciplinas de Desenho de Arquitetura (MELO et al, 1987, p.9-19). Desenho de Arquitetura / tinha o objetivo de 
Figura 1: Alunos desenhando a cidade de São Carlos, DAl, IAU-USP. Fonte: Fotografia de Daniela Hladkyi, 2015 desnaturalizar conceitos prévios de desenho dos estudantes ingressantes e incentivas o pensamento crítico. Para isso, utilizava a leitura de situações urbanas aliada a técnicas expressivas diversas. Desenho de Arquitetura // trabalhava sobre as normas de desenho técnico, articulando-se com as atividades das disciplinas de Projeto e História. Havia um trabalho integrado, avaliado em conjunto entre as disciplinas, com a temática das vanguardas modernas. Desenho de Arquitetura III trabalhava com composições gráficas a partir de leituras de situações urbanas.

Na revisão do curso em 1990, são implantados os ateliês de projeto integrado e as três disciplinas de desenho se reduzem a uma disciplina anual. Somente passaram a ser divididas por semestres mais recentemente, com a criação do IAU em 2010, que abriu novamente um espaço de discussão sobre o curso e revisão de seus programas e conteúdos.

Hoje, conta-se com apenas duas disciplinas, uma a cada semestre do primeiro ano do curso. Desenho de Arquitetura I trata de apresentar a sintaxe do desenho e representação gráfica, fazendo com que o aluno desenvolva sua percepção e expressão por meio do desenho à mão. Divide-se em dois módulos: no primeiro, a "desnaturalização do olhar" , pretende desmontar modelos pré-concebidos de representação gráfica e criar uma situação de atenção para o objeto percebido e o ato de desenho; no segundo, "olhar o espaço" pretende que o aluno seja sensibilizado pelos elementos da realidade cotidiana e urbana que o envolve, assim como os elementos constituintes de suas

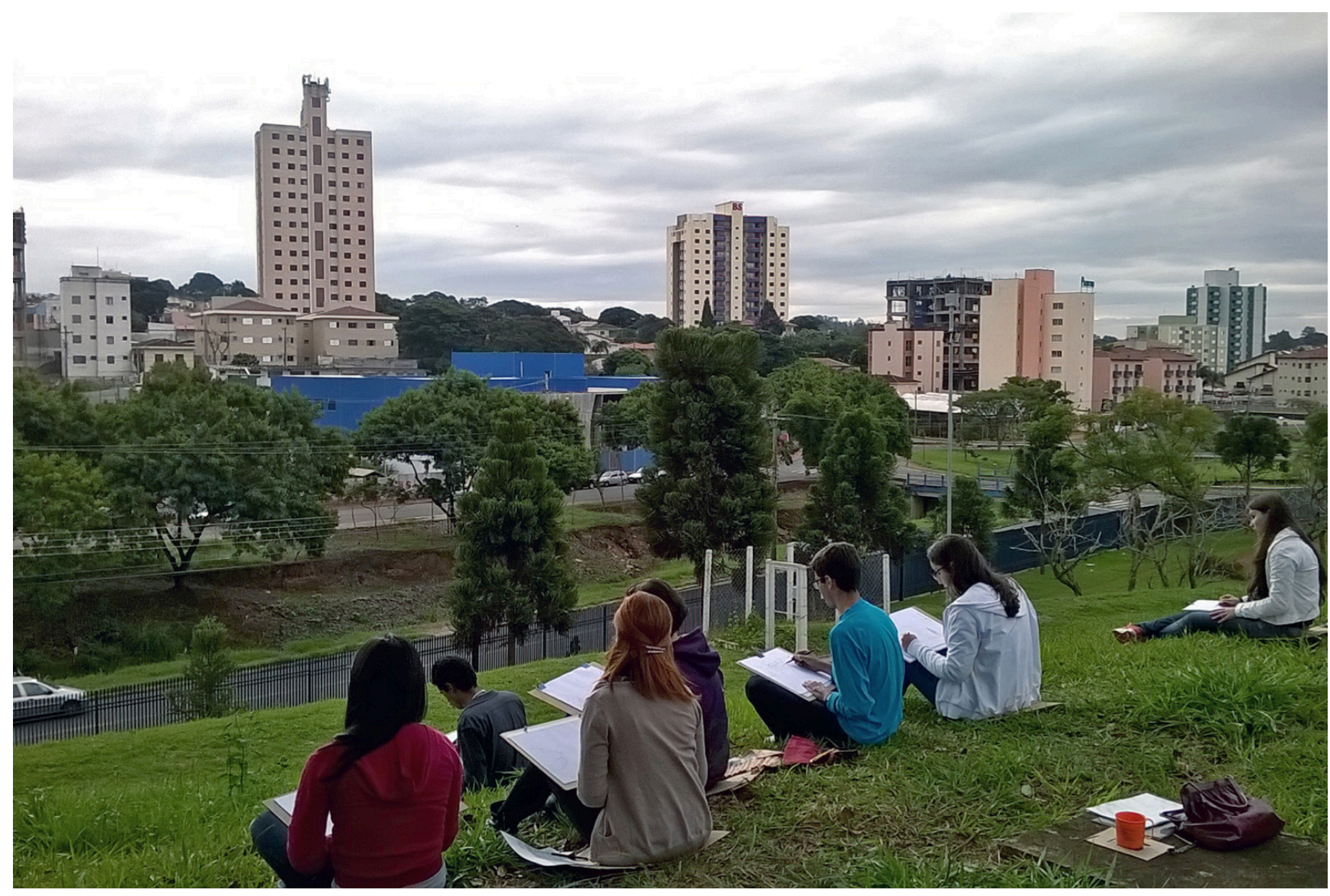

risco. 15_2 
Figura 2: Cadernos de viagem IAU-USP. Fonte: Fotografia de Daniela Hladkyi, 2015

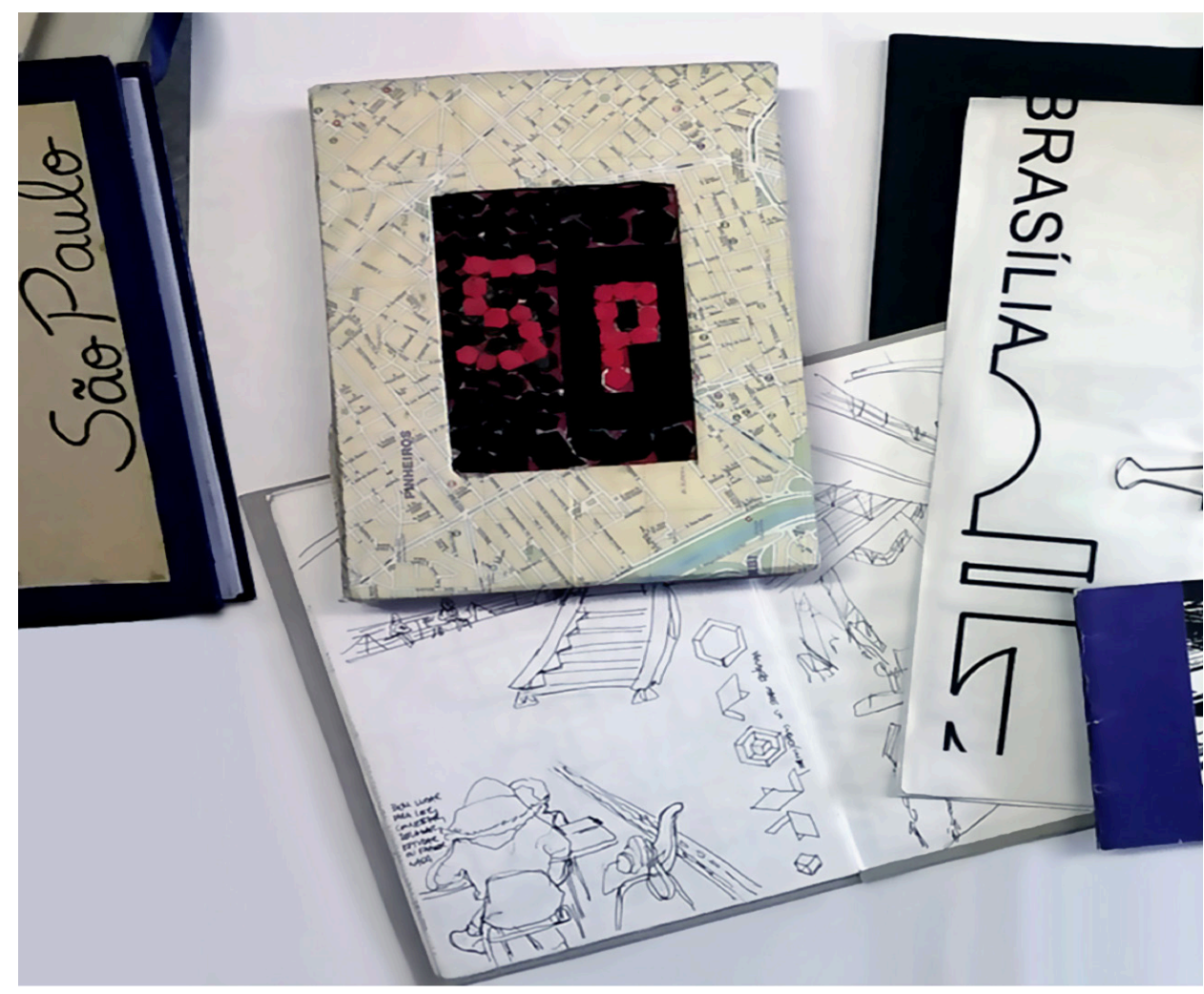

representações. A disciplina se desenvolve numa visão que passa da percepção de pequenos elementos cotidianos para o espaço escolar e chega à escala da cidade. Dentre as estratégias pedagógicas, predominam os exercícios de desenho cego, desenhos de estudo e desenhos de observação. Outro destaque é para o caderno de esboços e de viagem, a que os alunos são apresentados e convidados a confeccionar os seus, tanto para as atividades da disciplina, quanto para atividades de férias e da disciplina que implica na viagem didática a cidade de São Paulo que ocorre no semestre seguinte.

Desenho de Arquitetura // trata de desenvolver os sistemas de representação gráfica para arquitetura e suas normativas. Divide-se em dois momentos: no primeiro são introduzidos os instrumentos e normativas do desenho técnico à mão e à régua, onde os alunos desenvolvem pequenos exercícios de projeto, visando expor suas ideias por meio dos desenhos de projeções ortogonais, perspectiva isométrica e perspectivas com pontos de fuga. No segundo momento, há o desenrolar do exercício "ateliê de projeto", no qual os alunos desenvolvem um projeto individual com um programa tematizado pelos docentes e sistematizam a produção final. O resultado é a apresentação de um painel com a síntese do projeto.

O Ateliê de Projeto envolve um exercício sequenciado de criação e comunicação de projeto, aliando o aprendizado das normativas de desenho técnico arquitetônico no momento anterior. A exigência dos docentes desde o início desta disciplina é que o aluno entenda o processo de execução de cada desenho, realizando primeiramente à mão livre e depois com o auxílio dos instrumentos de desenho técnico, como régua paralela, esquadros e escalímetro. Assim, os alunos aplicam ao projeto as 
representações aprendidas como os croquis, as projeções ortogonais (desenhos em planta, elevações e cortes), além das perspectivas isométricas e cônicas, com 1 e 2 pontos de fuga. Este exercício dentro da disciplina de desenho é um momento de aplicação dos conhecimentos e de congruência entre o desenhar e o projetar. Por isso, o tema do exercício de projeto sempre se ampara em um programa muito aberto, no qual os alunos têm muita liberdade de criação, fazendo com que o processo gráfico e o repertório visual adquirido pelos estudantes até este momento fortaleçam as bases para a concepção projetual. (HLADKYI, 2017, p.191)

Entre o primeiro e segundo momentos desta disciplina, geralmente ocorre a viagem didática citada. Nesta viagem a cidade de São Paulo, os alunos acompanhados de grupos de professores que se alternam a cada dia, visitam vários lugares de interesse às diversas disciplinas cursadas no primeiro semestre do curso. Os alunos desenvolvem então um trabalho que tem por objetivo a síntese dos conteúdos e reflexões: consiste num caderno de viagem com os registros pessoais de cada aluno sobre os pontos visitados. Assim, as disciplinas de Desenho de Arquitetura contribuem diretamente no registro e meio de análise e reflexão sobre o espaço arquitetônico e urbano.

\section{Desenho na FAUP}

A FAUP tem uma história e tradição de longa data, que remonta às primeiras aulas públicas de Desenho e Debuxo em 1779 e se emaranham às origens da Escola de Belas-Artes do Porto. Tomamos como ponto de partida para discussão deste caso neste artigo, a configuração das disciplinas de desenho do curso de arquitetura criadas nos anos 1970 com as contratações dos professores artistas Alberto Carneiro e Joaquim Vieira e suas influências do modernismo na arquitetura, da escola Bauhaus, da Gestalt, da Black Mountain e dos artistas estruturalistas. Apesar de se contratarem até hoje docentes artistas plásticos, escultores ou pintores, o ensino de desenho sempre foi voltado para a formação em arquitetura. Os programas das disciplinas Desenho 1 e Desenho 2 se consolidam na década de 1980, fortalecidos pelo reconhecimento da pedagogia da Escola do Porto. Nela, o desenho foi tomado como instrumento privilegiado de projeto, fortemente evidenciado e valorizado por um conjunto de professores, entre eles Fernando Távora, Álvaro Siza, Alves Costa entre outros. Com o passar dos anos e as aposentadorias de Carneiro e Vieira, adequações foram feitas pelos novos professores regentes José Maria Lopes e Vitor Silva. Revisões se fizeram necessárias quando da implantação do Tratado de Bolonha: disciplinas se tornaram unidades curriculares e o curso passou a Mestrado Integrado em Arquitetura (MIArq) da FAUP.

Em Desenho 1 há a introdução da prática do desenho de observação a partir de exercícios bem estruturados em termos de proporção, medidas, enquadramento, regras de perspectiva etc. E da experimentação de uma vasta gama de técnicas de representação com os mais variados materiais de desenho. Os temas de desenho são vivenciados na realidade dos objetos do cotidiano, nos modelos vivos, no espaço escolar e nos cenários citadinos. Nesta unidade curricular não há qualquer atividade articulada conjuntamente com outra disciplina. Porém, podemos observar seu caráter propedêutico, que servirá de base para tantas outras dentro da estrutura do curso da FAUP, uma vez que o desenho foi eleito o instrumento de pensamento inerente à sua metodologia pedagógica teórico-prática. 
Figura 3: Alunos desenhando o espaço escolar, Desenho 2, FAUP. Fonte: Fotografia de Daniela Hladkyi, 2015.
Em Desenho 2 as técnicas aprendidas anteriormente são resgatadas, principalmente as regras de perspectivas cônicas e paralelas, para a representação de projetos de arquitetura, principalmente a partir de dados e espaços contextualizados na cidade real. Outras questões tomam forma sobre como representar aspectos conceituais de projeto, como utilizar o desenho para análise, estudo e comunicação de projeto. Além disso, os alunos experimentam e buscam uma expressão gráfica própria, desenvolvendo estudos adicionais para um projeto inserido na cidade real, paralelamente às atividades propostas pela unidade curricular de Projeto 2. Destacamos como exercícios de interesse entre as unidades curriculares: o diário gráfico e o painel de projeto.

Na FAUP, o Diário Gráfico pessoal é muito estimulado pelos docentes durante todo o curso de arquitetura, não somente nas disciplinas de desenho como também em outras disciplinas, visitas, viagens. É notável seu uso como caderno de esboços dos pensamentos relacionados à arquitetura disponível para qualquer momento. O diário registra não apenas desenhos de levantamentos de áreas de intervenção, como anotações sobre locais visitados, pormenores de arquitetura histórica, diagramas, fluxogramas, sistemas estruturais e construtivos, os primeiros esboços de um projeto aos detalhes de uma proposta final. Na unidade curricular de Desenho 2 o diário gráfico é mais requisitado que em outras disciplinas, sendo já pedido desde a primeira aula que os alunos adquiram ou façam um caderninho. Neste diário, os docentes assistentes orientam os alunos a registrarem as tarefas para casa e esboços que necessitarem durante as aulas e projetos. A unidade curricular Desenho 2 trabalha em paralelo à de Projeto 2 no segundo ano e tem como objeto de estudo comum um terreno ou área de intervenção de projeto arquitetônico. (HLADKYI, 2017, p.197-198)

O painel de projeto é desenvolvido a partir de diversas imagens que os alunos produzem para a proposta de Projeto 2. O exercício tem diversas etapas e trabalha

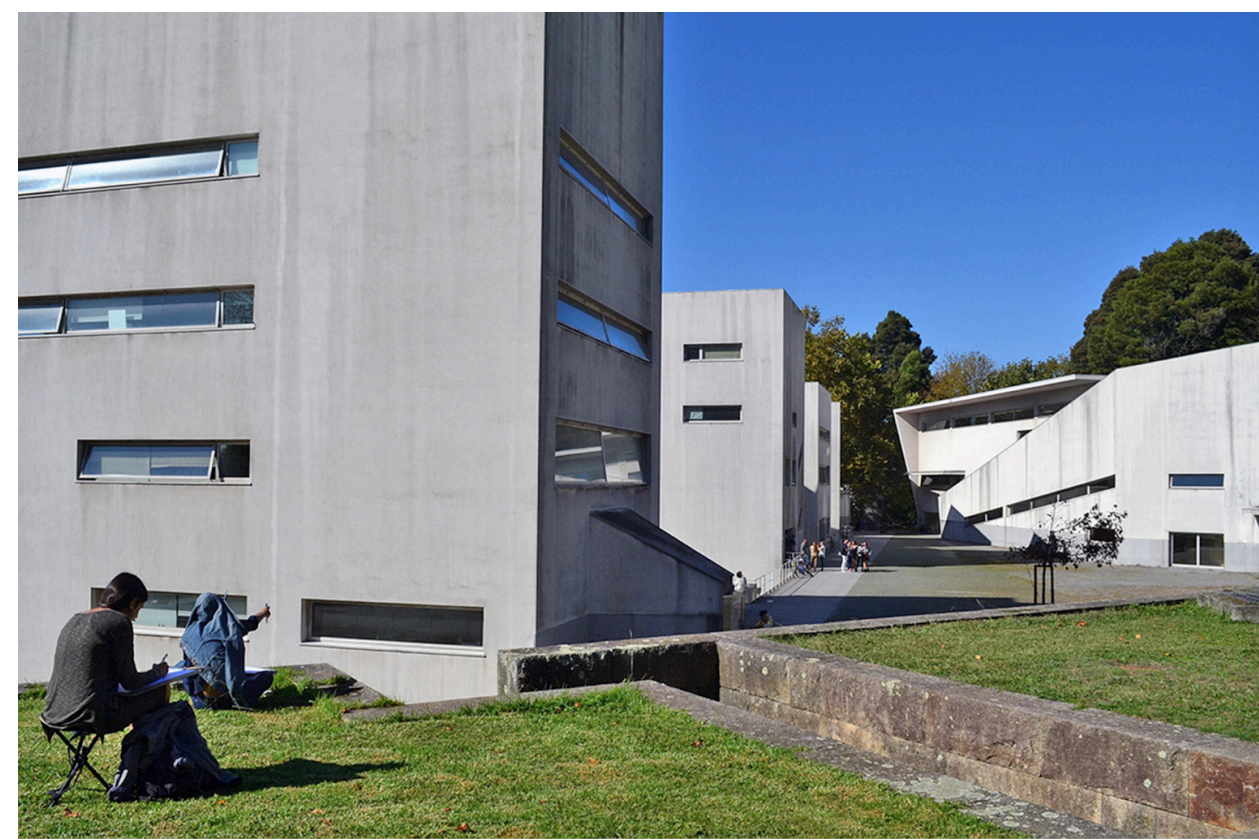


Figura 4: Mesa de trabalho de um aluno de Projeto 2, FAUP. Diário gráfico de Desenho 2 em primeiro plano, programa das edificações, planta de situação, isopor e materiais de desenho. Fonte: Fonte: Fotografia de Daniela Hladkyi, 2015..

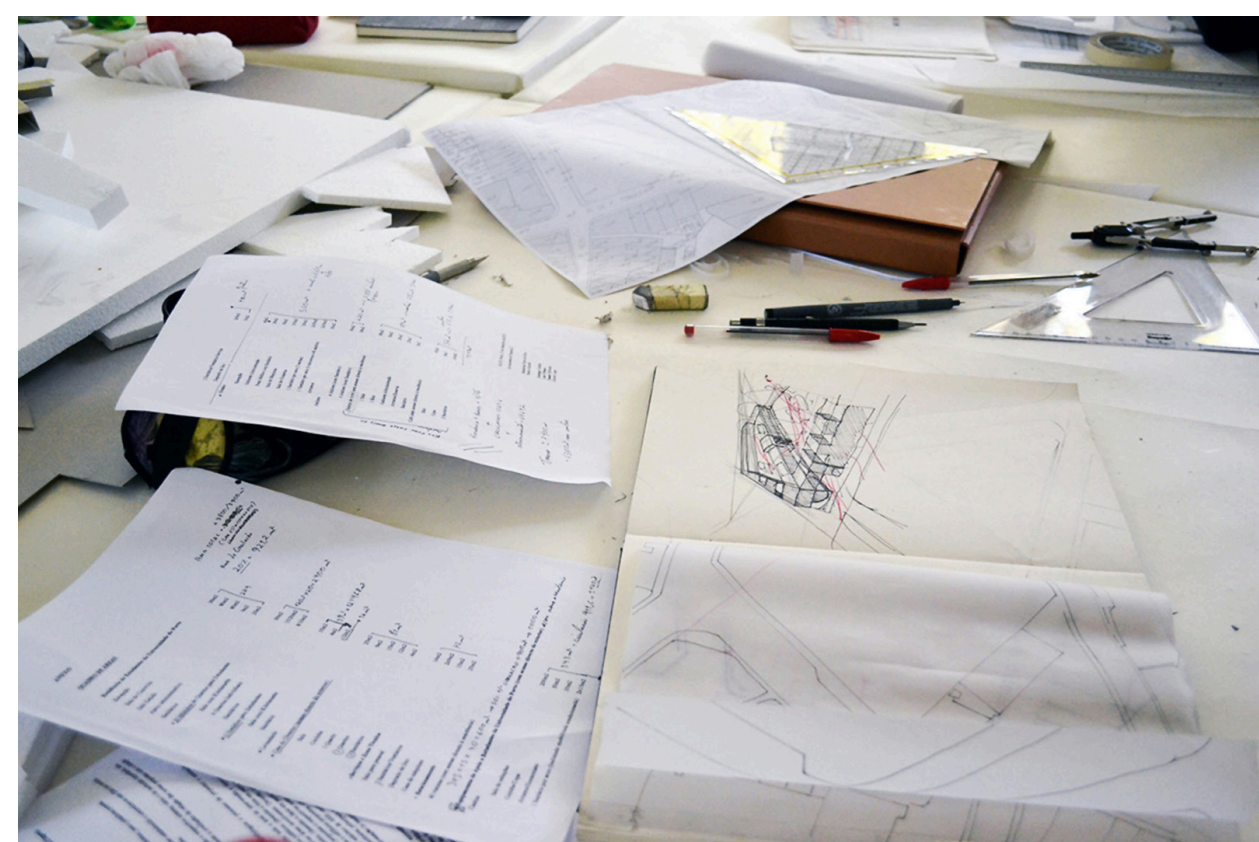

as diversas técnicas de representação gráfica sobre as perspectivas que os alunos produzem inicialmente: diversas imagens sequenciais de percursos na proposta de projeto, estudos de iluminação, cores e aplicação de materiais às superfícies. Depois exercitam a capacidade de seleção, articulação, montagem e composição de imagens para a comunicação e síntese do projeto.

Projeto 2 é uma unidade curricular de grande interesse no curso da FAUP, pois inaugura a atividade projetual sobre um terreno real na cidade do Porto. Os alunos recebem um vasto e detalhado programa a ser implantado no local e são orientados por docentes nas atividades de projeto, com instâncias de trabalho em grupo e individuais. A primeira aproximação da área de intervenção é a produção de 20 desenhos de observação à mão no diário gráfico, que são fixados às paredes para comentários. Depois, coletivamente, realizam uma maquete física e uma análise cinematográfica. Na sequência, aulas teóricas trazem conteúdo para embasar o processo projetual que ocorre alternadamente em atendimentos individualizados e coletivos. Primeiro realizam estudos em maquete física para depois passar ao desenho técnico, ainda sem muitos detalhes a plantas esquematizadas. O diário gráfico traz os apontamentos de informações e estudos do projeto assim como diversos produstos pedidos pelos docentes.

\section{O desenho em transversalidade}

Retomando as delimitações dos termos multi, transe interdisciplinaridade, observaremos suas ocorrências nas disciplinas de desenho das duas instituições estudadas.

Primeiramente, com relação às disciplinas de desenho no IAU-USP, Desenho de Arquitetura I não propõe atividades interdisciplinares, porém trabalha a expressão gráfica e a elaboração do caderno de viagem que serão utilizados na disciplina do 
Figura 5: Exposição Anuária 2015, cadernos de viagem de História, FAUP. Fonte: Fotografia de Daniela Hladkyi, 2015. semestre seguinte que corresponde à viagem didática à cidade de São Paulo. A disciplina da viagem se configura isoladamente na grade curricular, porém resgata e articula os conteúdos das diversas disciplinas cursadas no primeiro semestre do curso, o que poderíamos considerar como uma atividade interdisciplinar.

Desenho de Arquitetura // também não propõe atividades interdisciplinares, porém realiza um exercício de projeto. Os professores já tentaram propor tal exercício conjuntamente com a disciplina de Projeto I, porém as dificuldades em alinhar as atividades e conciliar as agendas de docentes inviabilizaram uma integração. Assim, o exercício acontece isoladamente dentro da disciplina de desenho, mas funciona como um campo de teste para a projetação com o suporte dos docentes de desenho, o que o tornaria uma atividade multidisciplinar.

Com relação às unidades curriculares de desenho na FAUP, Desenho 1 também não propõe atividades interdisciplinares. Porém trabalha a prática do desenho expressivo de arquitetura, que será a base sólida para o aprendizado em muitas outras disciplinas ao longo do curso: tanto para as de Projeto, CAAD, como as de História. O desenho é de extrema relevância no curso e pode-se verificar isso visivelmente nas exposições Anuária, que ocorrem a cada ano e apresentam os produtos desenvolvidos pelos alunos da turma anterior. Podemos dizer que o desenho é o elemento da transversalidade entre as unidades curriculares.

Já Desenho 2 tem uma postura interdisciplinar com Projeto 2, principalmente ao adotar o mesmo terreno como objeto de estudo e experimentação gráfica. Ainda que cada unidade curricular trabalhe e avalie seus próprios produtos, o diário gráfico desenvolvido pelos alunos é compartilhado entre ambas unidades curriculares e alimenta o processo de projeto e as experimentações gráficas de desenho.

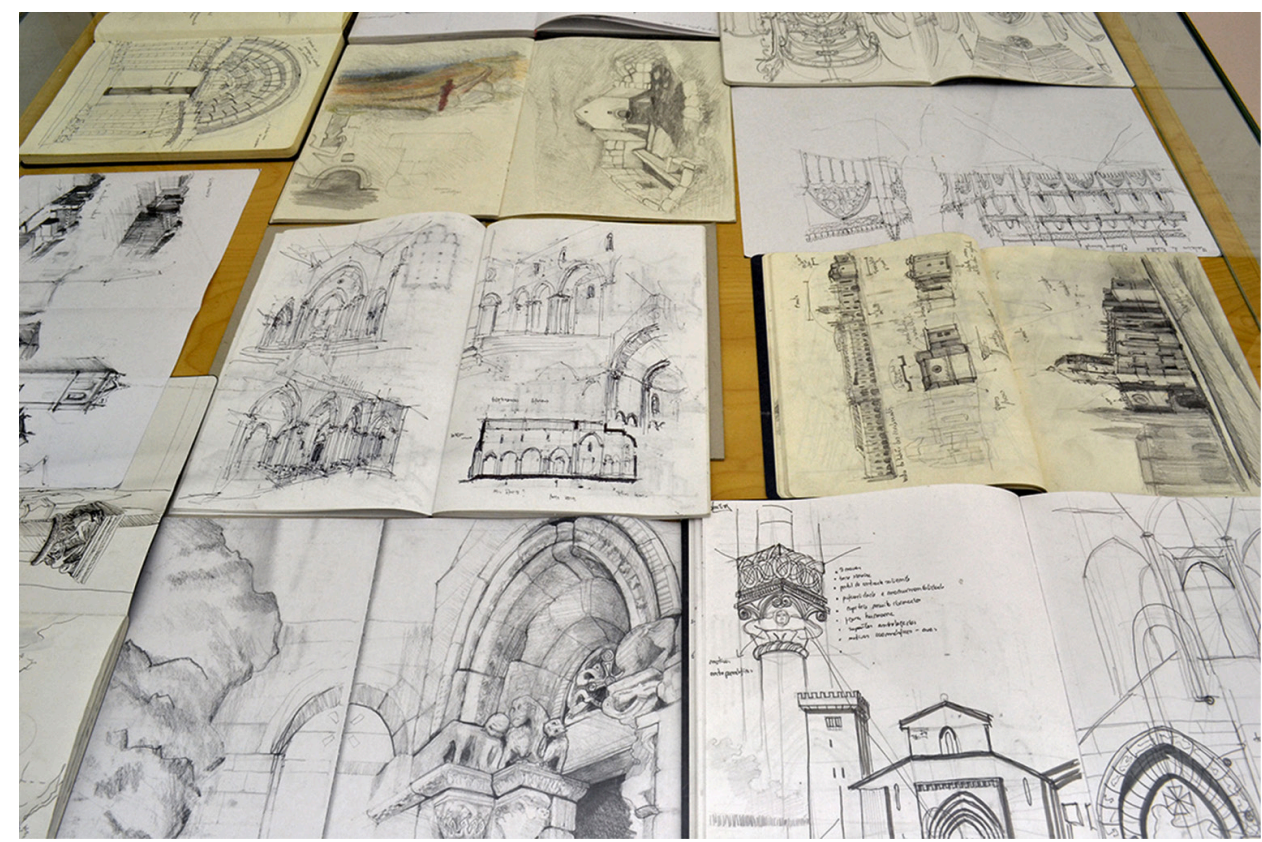


Figura 6: Exposição Anuária 2015: pranchas de Projeto, cadernos de viagem de História etc., FAUP. Fonte: Fotografia de Daniela Hladkyi, 2015.

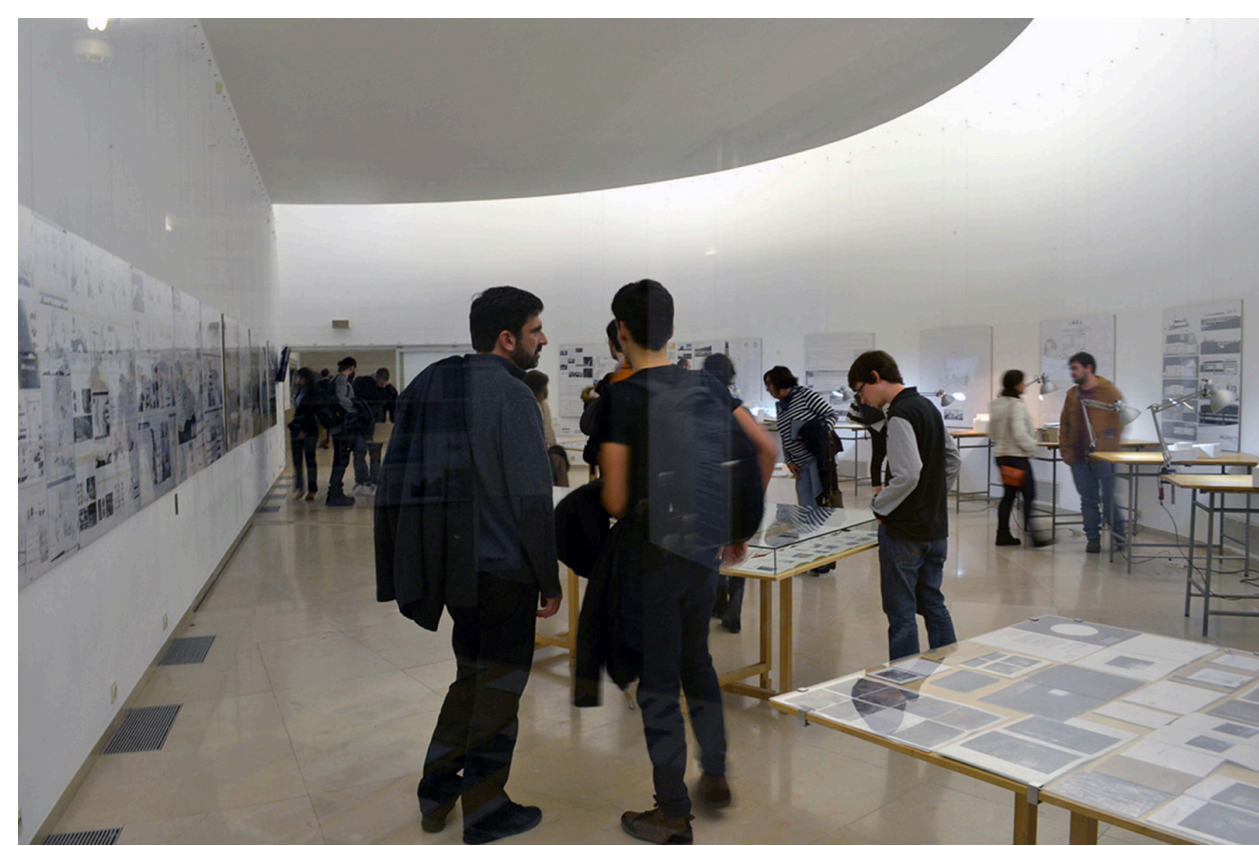

Para finalizar, comparando as atividades realizadas pelas duas instituições, notamos o desenho à mão como interesse das estratégias didáticas, num horizonte onde cada vez mais as atividades projetuais são pautadas pelo uso do computador e de softwares muito especializados e diversas faculdades tem até mesmo abolido o ensino do desenho à mão. Esse interesse no desenho à mão, tanto pelo IAU como pela FAUP, se baseia nas qualidades e potencialidades criativas que o desenho pode ampliar e interferir no pensamento e processo projetual, ou mesmo no aprendizado de outras competências dentro de cada curso. Esse caráter transversal inerente ao desenho nos cursos de arquitetura é uma alternativa que pode ser incentivada, ter fácil aplicação e abre campos de experimentações e aprendizados mais fortalecidos.

No caso do IAU, o desenho em relação interdisciplinar na viagem didática no primeiro ano, auxilia a síntese de conteúdos e na capacidade dos alunos refletirem sobre espaços e situações urbanas vivenciadas. Notamos o esforço de atualizar o oferecimento das disciplinas de Desenho de Arquitetura no IAU-USP mais próximos à realidade pensante do processo de projeto, mas o distanciamento das disciplinas de Projeto em si expõe o isolamento das disciplinas, a falta de colaboração e deixa de conquistar um espaço de aprendizado potencialmente mais concreto e dinâmico.

No caso da FAUP, o reconhecimento deste potencial do desenho como instrumento no aprendizado de arquitetura já acontece. O desenho é elemento transversal a todo o curso. Várias disciplinas elegem o desenho como produto ou o incluem em seus processos de projeto e pesquisa. O que poderia ser fortalecido neste curso seriam as relações interdisciplinares. Uma vez que algumas unidades curriculares poderiam integrar-se ainda mais. É o caso de Desenho 2 e Projeto 2 na FAUP, que já trabalham paralelamente, porém independentemente em suas atividades dentro de cada unidade 
curricular, onde professores arquitetos de projeto pouco interagem com professores artistas de desenho. Certeiramente, o diário gráfico é a fronteira tênue, mas que articula, amplia a atuação e colaboração entre as estas unidades curriculares.

Observar tais relações de articulação entre disciplinas possibilita visualizar o lugar do desenho atualmente dentro dos cursos estudados e a partir disso, avaliar e repensar os programas das disciplinas, a colaboração entre docentes e os potenciais ganhos no processo de aprendizado dos alunos a partir de atividades interdisciplinares.

\section{Referências bibliográficas}

FAZENDA, Ivani (Org.). O que é interdisciplinaridade? São Paulo: Cortez Editora, 2008.

HLADKYI, Daniela Zavisas. Desenho em observação: o ensino de desenho nos cursos de arquitetura da FAUP e do IAU. 2017. Dissertação (Mestrado em Teoria e História da Arquitetura e do Urbanismo) - Instituto de Arquitetura e Urbanismo, Universidade de São Paulo, São Carlos, 2017. Disponível em: <http://www.teses.usp.br/teses/disponiveis/102/102132/ tde-04092017-151456/pt-br.php >. Acesso em 15 nov. 2017.

HLADKYI, Daniela Zavisas. Desenhos e fotografias de acompanhamento dos estágios nas disciplinas DAI no IAU-USP e Desenho 1, Desenho 2 e Projeto 2 na FAUP. São Carlos/Porto: IAU-USP/FAUP, 2015.

MELO, Francisco Inácio Homem de; PINTO, Gelson de Almeida; FERRARI, Marisa; ANELLI, Renato Luiz Sobral (Org.). Arquitetura Mostra Trabalhos. Catálogo da exposição: Arquitetura Mostra Trabalhos, realizada entre 10 e 20 de março de 1987 no Centro Cultural do campus da USP de São Carlos, expondo trabalhos curriculares das turmas ingressantes em 1985 e 1986 no Curso de Graduação em Arquitetura. Universidade de São Paulo, Escola de Engenharia de São Carlos: São Carlos, 1987.

MERLEAU-PONTY, Maurice. Fenomenologia da percepção. Phénoménologie de la perception (1945). Tradução Carlos Alberto Ribeiro de Moura. $4^{a}$ ed. São Paulo: Editora WMF Martins Fontes, 2011

PIAGET, Jean. L'Epistémologie des reations interdisciplinaires. L'interdisciplinarité: problèmes d'enseignement et de recherche dans les universités. Paris: OCDE, 1972, p.154-171. Disponível em: < http://www.fondationjeanpiaget.ch/fjp/site/textes/NE/jp72_epist_relat_interdis. pdf $>$. Acesso em 15 nov. 2017.

POMBO, Olga. Interdisciplinaridade e integração dos saberes. Liinc em Revista, v.1, n. 1, março 2005, p.3-15. Disponível em: <http://www.ibict.br/liinc>. Acesso em 15 nov. 2017.

SANTOS, Fábio Lopes Souza; CASTRAL, Paulo César. Espacialidade Moderna: fundamentos para revisão do repertório plástico. In: XIII Congreso Arquisur. Libro de Ponências - La enseñanza de la arquitetura. Santa Fé, Argentina: Ediciones FADU-UNL, 2009. p.143-149. 